\title{
Preparation and Characterization of Water-Dispersible Silver Nanoparticles Stabilized by PEO-Conjugated Pro-Drugs
}

\author{
Tae Hwan Kim, Keunsuk Kim, Geon Hee Park, Jin Hee Choi, Sangmi Lee, Ho-Jung Kang, \\ Jae Yeol Lee, and Jungahn Kim* \\ Department of Chemistry, Kyunghee University, Seoul 130-701, Korea
}

Received January 15, 2009; Revised March 4, 2009; Accepted August 11, 2009

\begin{abstract}
Anhydride-functionalized poly(ethylene oxide) (PEO) obtained from chain-end functionalization and anionic ring-opening polymerization of ethylene oxide using $n$-butyllithium with potassium $t$-butoxide in the presence of dimethylsulfoxide (DMSO) was found to be an efficient material for the preparation of water-soluble, polymeric pro-drugs. The reaction of $\omega$-anhydride-functionalized PEO with sulfonamide or with vancomycin provided an efficient method to produce corresponding, water-soluble, PEO-conjugated sulfonamide or PEO-conjugated, vancomycin pro-drugs. These were used successfully to prepare water-dispersible, silver nanoparticles. In this study, the particle sizes were in the range of $5 \sim 40 \mathrm{~nm}$. The resulting products were characterized by ${ }^{1} \mathrm{H}$ NMR spectroscopy, transmission electron microscopy, electron and X-ray diffraction, size exclusion chromatography, and UV/Visible spectroscopy.
\end{abstract}

Keywords: water-dispersible Ag nanoparticle, PEO-conjugated pro-drugs, PEO-sulfadiazine.

\section{Introduction}

Recent studies on the synthesis of nano-sized metal particles have received a great attention because of a variety of their application fields including information technology and bio-technology fields. ${ }^{1-7}$ The development of synthetic procedures of nano-sized silver and iron oxide clusters becomes a key subject in the academic as well as the industrial fields because of their size- and shape-dependencies of optoelectronic, ${ }^{8,9}$ magnetic, ${ }^{10}$ and catalytic ${ }^{11}$ properties.

It has been reported that a controlled growth of silver nanocrystals can lead to the formation of a variety of welldefined silver nanostructures. ${ }^{12,13}$ Furthermore, nano-sized silver particles are well-known to be used in many bactericidal and antimicrobial applications. ${ }^{14,15}$ The development of an efficient method for preparation of poly(ethylene oxide)-stabilized water-soluble silver nanoparticles may contribute to find analogously synthetic routes for waterdispersible metal nanoparticles such as gold. Poly(ethylene glycol) (PEG) having the same architecture as PEO with relatively low molecular weight (depending on synthetic condition) in biomedical application field has been employed for a long time because it is cheap, water-soluble and biocompatible. ${ }^{8}$ In this respect, the combination of these two substances (pro-drug/silver) seems to provide a synergistic effect in the biomedical as well as the nanotechnology field.

*Corresponding Author. E-mail: jakim05@khu.ac.kr
A number of ions of monocarboxylic and dicarboxylic acids have been found to be very effective to stabilize silver surfaces for a long time. ${ }^{16}$ Polymeric materials such as poly (vinyl pyrrolidone)(PVP) carrying amine functional group are also reported to be a good stabilizer for the silver nanoparticle. ${ }^{13}$ In addition, both vancomycin and sulfadiazine have been well-known as highly active antibacterial drugs for a long time. ${ }^{17-19}$ Concerning these observations, PEO-vancomycin or PEO-sulfadrug conjugates as precursors of prodrugs must be effective to stabilize silver surface because they retain the active functional groups at the polymeric chain-ends playing an important role to stabilize metal surfaces by ionic-dipole or ionic-ionic interaction.

In this paper, we report the results for preparation of nanosized silver particles stabilized by PEO-based pro-drugs such as PEO-sulfadiazine and PEO-vancomycin conjugates prepared via chain-end functionalization of 'living' polymeric alkoxide produced by $n$-butyllithium-initiated polymerization of EO in the presence of potassium $t$-butoxide in the mixture of benzene/dimethyl sulfoxide.

\section{Experimental}

Materials. Tetrahydrofuran (THF; Oriental Chem. Co., reagent grade), benzene (Dae Jung Chem. Co., reagent grade), and methanol (Oriental Chem. Co., reagent grade) were purified by following the procedures described in the literatures. ${ }^{20}$ Sulfadiazine (Sigma Chem. Co.) and vancomycin 
(Sigma Chem. Co., reagent grade) were used as purchased without further purification. Trimellitic anhydride chloride (TMAC; Aldrich Chem. Co., 99\%) was also used as purchased. Ethylene oxide (Aldrich Chem. Co., 99.5\%+) was dried with $\mathrm{CaH}_{2}$ below $5{ }^{\circ} \mathrm{C}$ under high vacuum for at least $3 \mathrm{~h}$, followed by distillation of required amount into calibrated cylinder. ${ }^{21}$ Potassium tert-butoxide ( $t$-BuOK; Aldrich Chem. Co., 1.0 M solution in tetrahydrofuran) was also purchased and used without further purification. $n$-Butyllithium $(n$-BuLi; Aldrich Chem. Co., 1.6 M in hexane) was used as an initiator after titration by Gilman's method using 1,2-dibromoethane. ${ }^{22}$

Polymerization and Functionalization. As already described in the literatures, ${ }^{21,23} n$-BuLi-initiated ring-opening polymerization of ethylene oxide with potassium tert-butoxide was performed in the mixture of benzene/dimethyl sulfoxide $(10 / 1, \mathrm{v} / \mathrm{v})$ at $30-40{ }^{\circ} \mathrm{C}$ for $48 \mathrm{~h}$ under high vacuum; $n$ $\operatorname{BuLi}\left(3.5 \times 10^{-3} \mathrm{~mol}\right)$ reacted with purified EO $(40 \mathrm{~mL})$ in $400 \mathrm{~mL}$ of the mixture of benzene/THF (99/1, v/v) for $6 \mathrm{~h}$, followed by adding $40 \mathrm{~mL}$ of dimethylsulfoxide (DMSO) and $t$-BuOK $\left(3.5 \times 10^{-3} \mathrm{~mol}\right)$ solution into the reactor $\left(\left[\mathrm{K}^{+}\right] /\right.$ $\left[\mathrm{Li}^{+}\right]=1 / 1 \mathrm{~mol} / \mathrm{mol}$ ) via the break-seal technique, standing the solution with stirring at $35^{\circ} \mathrm{C}$ with intermittently cooling down to $0{ }^{\circ} \mathrm{C}$ and heating to $35^{\circ} \mathrm{C}$ for $48 \mathrm{~h}$. After an aliquot was taken, the trimellitic anhydride chloride $\left(\left\{\left[\mathrm{Li}^{+}\right]+\right.\right.$ $\left.\left[\mathrm{K}^{+}\right]\right\} /[\mathrm{TMAC}]=1 / 5, \mathrm{~mol} / \mathrm{mol}$ ) THF solution was delivered into the remained solution of the reactor via a break-seal technique and the reactor stood at room temperature for $24 \mathrm{~h}$ with vigorously stirring. After complete reaction, the polymer solution was precipitated into excess diethyl ether, followed by filtration and drying in vacuum oven at room temperature for at least $48 \mathrm{~h}$. A calculated amount of sulfadiazine $(\mathrm{FW}=250.52)$ and that of $\omega$-anhydride PEO $\left(M_{n}=\right.$ $5,100 \mathrm{~g} / \mathrm{mol}$ ) ([Sulfadiazine $] /[\omega$-anhydride PEO $]=0.2 / 0.2$, $\mathrm{g} / \mathrm{g}$ ) was dissolved in the mixture solution of tetrahydrofu$\mathrm{ran} / \mathrm{methanol}(60 / 5, \mathrm{~mL} / \mathrm{mL})$ with a drop of $\mathrm{HCl}(0.2 \mathrm{~mL}$, $95 \%$ aqueous) to make an acidic condition and the reaction proceeded at room temperature for $48 \mathrm{~h}$, followed by precipitation in excess diethyl ether and removal of excess sulfadiazine unreacted. PEO-conjugated vancomycin (PEOvancomycin) as shown in Figure 1 was prepared by following the similar synthetic procedures to those of PEO-conjugated sulfadiazine (PEO-sulfadiazine); $1 \mathrm{~g}$ of $\omega$-anhydride PEO $\left(M_{n}=6,000 \mathrm{~g} / \mathrm{mol}\right)$ and $0.6 \mathrm{~g}$ of vancomycin $(\mathrm{FW}=1,485.75)$ were dissolved in $60 \mathrm{~mL}$ of dimethyl sulfoxide with vigorously stirring and the reaction proceeded at $55^{\circ} \mathrm{C}$ for $48 \mathrm{~h}$, followed by precipitation in excess diethyl ether and removal of excess vancomycin unreacted. The resulting products were dried in vacuum oven at room temperature for $48 \mathrm{~h}$ prior to the use.

Preparation of Nano-Sized Silver particles. Using the PEO-sulfadiazine and the PEO-vancomycin, nano-sized silver particles were prepared in methanol; first, $0.02 \mathrm{~g}(1.2 \times$ $\left.10^{-4} \mathrm{~mol}\right)$ of $\mathrm{AgNO}_{3}(\mathrm{FW}=169.88)$ and $1.06 \mathrm{~g}\left(2.0 \times 10^{-4} \mathrm{~mol}\right)$ (a)
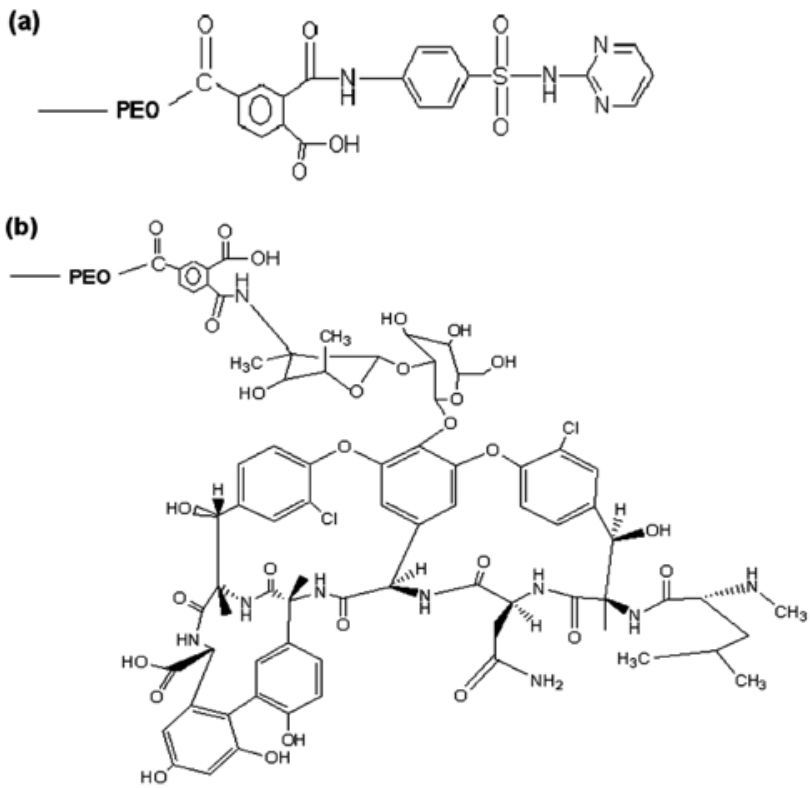

Figure 1. Chemical structures of PEO-conjugated pro-drugs; (a) PEO-sulfadiazine and (b) PEO-vancomycin.

of PEO-sulfadiazine $\left(M_{n}=5,300 \mathrm{~g} / \mathrm{mol}\right)$ were dissolved in methanol $(60 \mathrm{~mL})$, followed by adding $23 \mathrm{mg}$ of $\mathrm{NaBH}_{4}$ $\left(2.4 \times 10^{-3} \mathrm{~mol}\right)$ as a reducing agent and keeping the reaction at room temperature for $24 \mathrm{~h}$. Using PEO-vacomycin prodrug as a stabilizing agent, silver nanoparticles were also obtained in aqueous media; $0.02 \mathrm{~g}\left(1.2 \times 10^{-4} \mathrm{~mol}\right)$ of $\mathrm{AgNO}_{3}$ $(\mathrm{FW}=169.88)$ and $0.5 \mathrm{~g}\left(5.0 \times 10^{-5} \mathrm{~mol}\right)$ of vancomycin-PEO $\left(M_{n, o b s}=10,000 \mathrm{~g} / \mathrm{mol}\right)$ were dissolved in distilled water $(60 \mathrm{~mL})$, followed by adding $25 \mathrm{mg}\left(6.6 \times 10^{-4} \mathrm{~mol}\right)$ of $\mathrm{NaBH}_{4}(\mathrm{FW}=$ 37.83 ) as a reducing agent and keeping the reaction at room temperature for $8 \mathrm{~h}$, followed by precipitation in diethyl ether and re-dispersion in distilled water.

Characterization. Size exclusion chromatographic (SEC) analysis was performed at a flow rate of $1.0 \mathrm{~mL} / \mathrm{min}$ in THF at $30^{\circ} \mathrm{C}$ using the Dionex Softron P680 HPLC component system equipped with two Shodex GPC columns (LF-804) and two ultra- $\mu$-Styragel columns ( $500 \AA$ ) with Wyatt Technology Interferometric Refractometer MALLS system after calibration with standard poly(ethylene oxide) samples (Polymer Laboratories) and SEC analysis of product was also performed using a Water GPC 410 system equipped with three UltrahydrogelTM $(120,150,500 \AA)$ at a flow rate of $0.6 \mathrm{~mL} /$ min in distilled $\mathrm{H}_{2} \mathrm{O}$ containing $5 \% \mathrm{NH}_{4} \mathrm{OH}$. ${ }^{1} \mathrm{H}$ NMR spectroscopic analysis was performed using a Bruker spectrometer (Model; Avance $400(400 \mathrm{MHz})$ ) in deutrated dimethylsulfoxide (Aldrich Chem. Co.) or $\mathrm{CDCl}_{3}$ at $25^{\circ} \mathrm{C}$. The \%transmittance change in distilled $\mathrm{H}_{2} \mathrm{O}$ and buffer solution was monitored using an Agilent 8453 Diode Array spectrophotometer. The formation of water-soluble siliver nanoparticles was confirmed by the combination of TEM images, electron diffraction, and X-ray diffraction patterns. 


\section{Results and Discussion}

Synthesis of PEO-Based Pro-Drugs. Chain-end functionalizations of polymeric alkoxides synthesized from $n$-butyllithium-initiated ring-opening polymerization of $\mathrm{EO}$ in the presence of $t$-BuOK were successfully performed. ${ }^{21,23}$ Not only quantitative chain-end functionalization but also control of molecular weight of polymeric alkoxide generated by following anionic manner in ring-opening polymerization of ethylene oxide may be achieved as desbribed in the previous literature. ${ }^{23}$ The functionalization yields based on the results for thin-layer chromatographic (TLC) analysis qualitatively and ${ }^{1} \mathrm{H}$ NMR spectroscopic analysis quantitatively were over 90 mol- $\%$. Among them, $\omega$-anhydride PEO may be effectively utilized to improve the water-solubility of waterinsoluble drugs. ${ }^{24}$ Practically, PEO-based prodrugs such as PEO-conjugated sulfadiazine and PEO-conjugated vancomycin were able to be readily prepared by following the reaction procedures as shown in Scheme I.

Figure 2 shows size exclusion chromatograms of $\omega$-anhydride-PEO and the corresponding PEO-sulfadiazine conjugate run by using water as an eluent.

The molecular weight of poly(ethylene oxide) was controlled to $5,100 \mathrm{~g} / \mathrm{mol}$ exhibiting 1.10 of polydispersity. Figure 3 represents ${ }^{1} \mathrm{H}$ NMR spectrum of PEO-sulfadiazine conjugate obtained from the reaction of $\omega$-anhydride PEO with sulfadiazine. The chemical shifts in the range of 7.2$8.6 \mathrm{ppm}$ correspond to the protons on phenyl rings of the sulfadiazine group and the trimellitic anhydride group. The functionalization yield was ca. $85 \mathrm{~mol}-\%$ on the basis of ${ }^{1} \mathrm{H}$ NMR spectroscopic analysis on the basis of incorporation of sulfadiazine at the chain-end.

Preparation of Silver Nanoparticles. Silver nanoparticles were prepared by reduction of $\mathrm{AgNO}_{3}$ with $\mathrm{NaBH}_{4}$ as a

Scheme I.

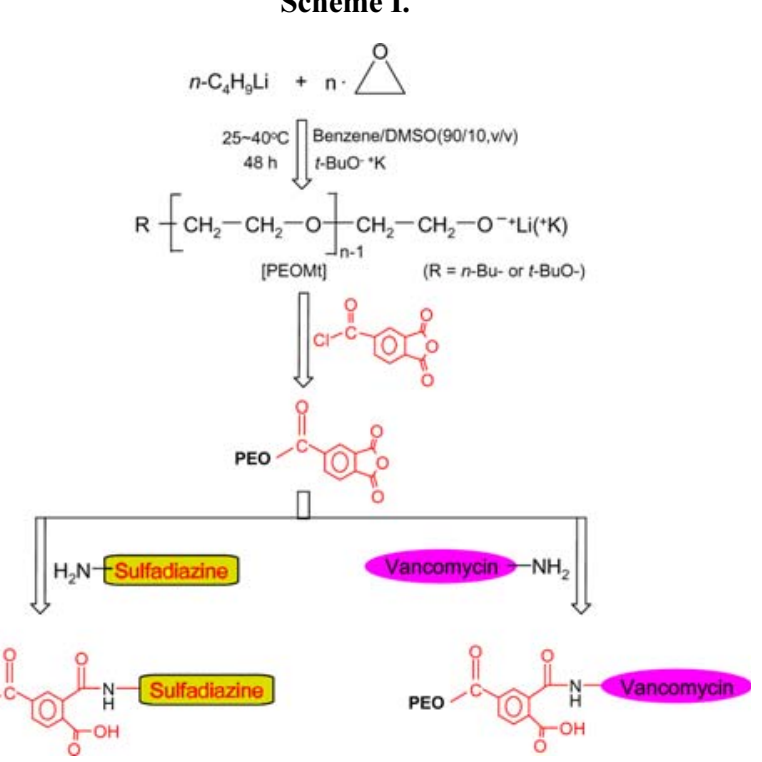

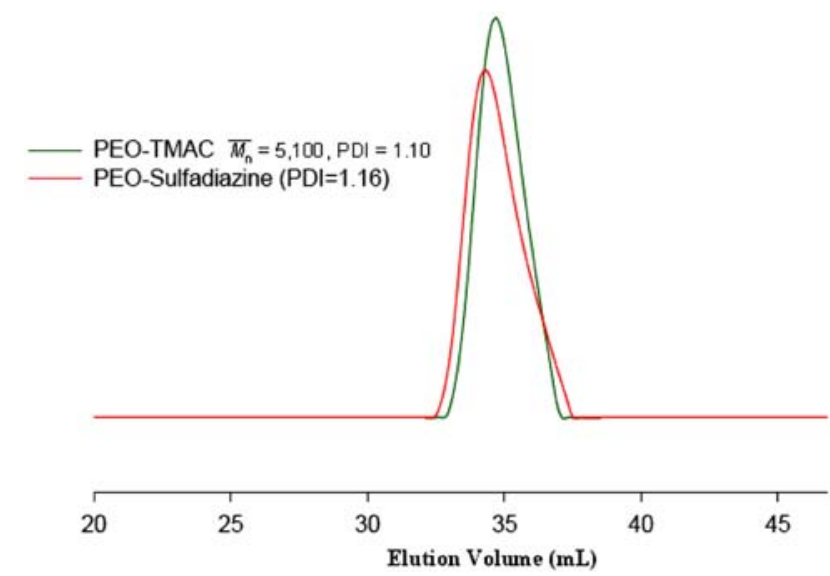

Figure 2. Comparison of size exclusion chromatograms of $\omega$ anhydride-PEO and the corresponding PEO-sulfadiazine conjugate using $\mathrm{H}_{2} \mathrm{O}$ as an eluent.

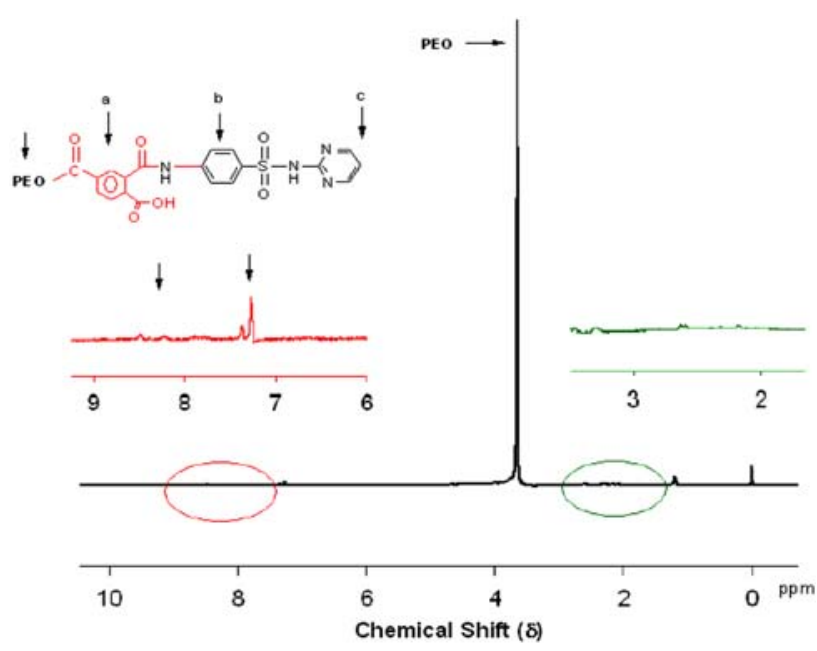

Figure 3. ${ }^{1} \mathrm{H}$ NMR spectrum of PEO-sulfadiazine conjugate shown in Scheme I.

reducing agent in the presence of PEO-sulfadiazine conjugate as a steric stabilizing agent in methanol. The optical properties of nano-sized transition metals are directly related to their surface plasomon resonances ascribing to a collective oscillation of conduction electrons in response to optical excitation, which are strongly size- and shape-dependent. ${ }^{25}$ It has been found that $C_{s}$ symmetrical nano-sized spheres have only one peak, whereas $O_{h}$ symmetrical cubic particles show three peaks. ${ }^{26}$ In addition, three optical spectral peaks in the case of triangular silver nanoplates were reported to be observed at $\lambda_{\max }=335,470$, and $690 \mathrm{~nm} .{ }^{25}$ As shown in Figure 4, while PEO-sulfadiazine conjugate itself exhibits the weak absorption peaks at $\lambda_{\max }=400 \mathrm{~nm}$ and $620 \mathrm{~nm}$, only one broad absorption peak at $\lambda_{\max }=400 \mathrm{~nm}$ in the case of PEO-sulfadiazine-stabilized Ag-nanoparticles in water informs that the nanoparticles seem to be spherical particles exhibiting symmetrical cubic lattice structure. A broad absorption 


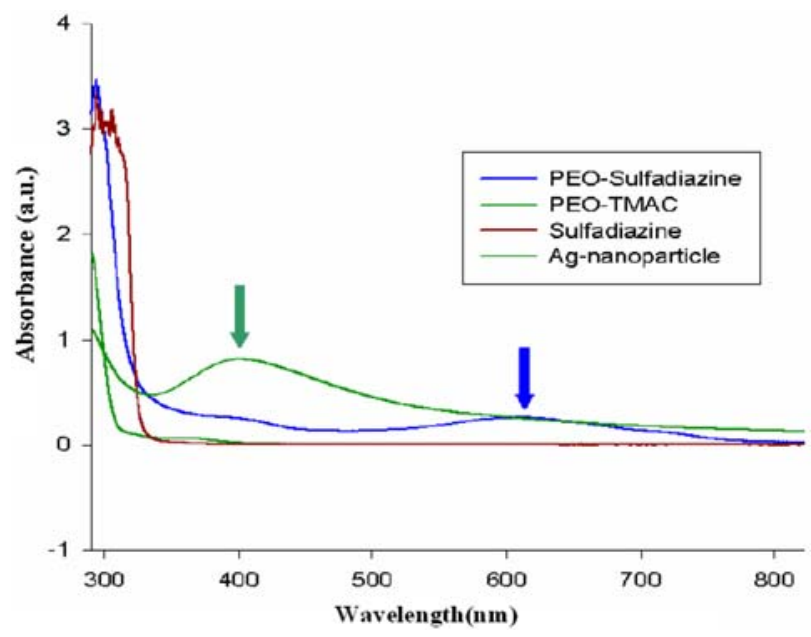

Figure 4. The electric spectral change of PEO-stabilized Ag nanoparticles and the corresponding PEO-based polymers in methanol.
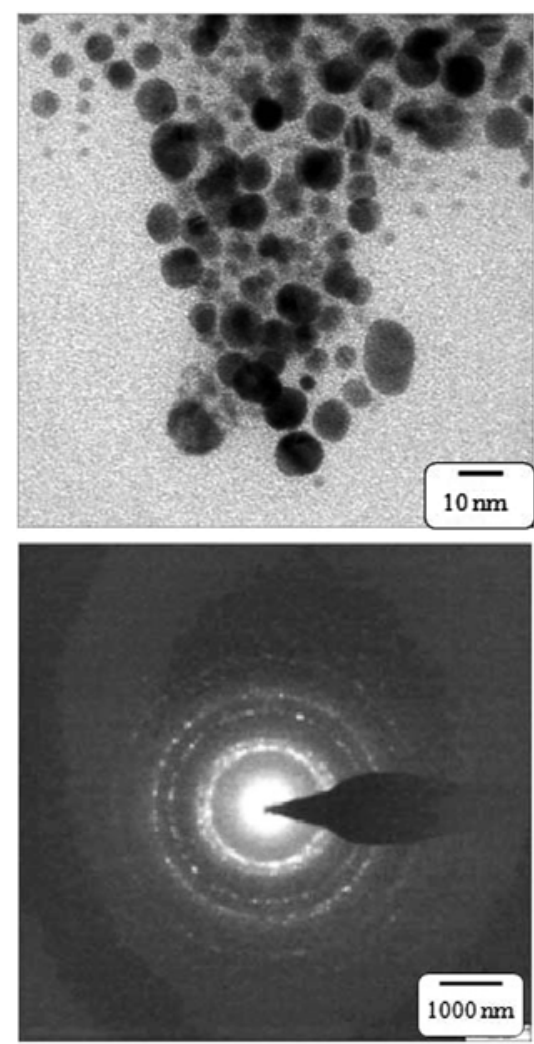

Figure 5. TEM image and ED pattern of PEO-sulfadiazine-stabilized silver nanoparticles.

band of nano-sized metal particles indicates that the size distribution of particles formed are not uniform.

The TEM image of silver nanoparticle and its electron diffraction pattern are shown in Figure 5. As already described, the particle size distribution looks broad in the range of $5-30 \mathrm{~nm}$.

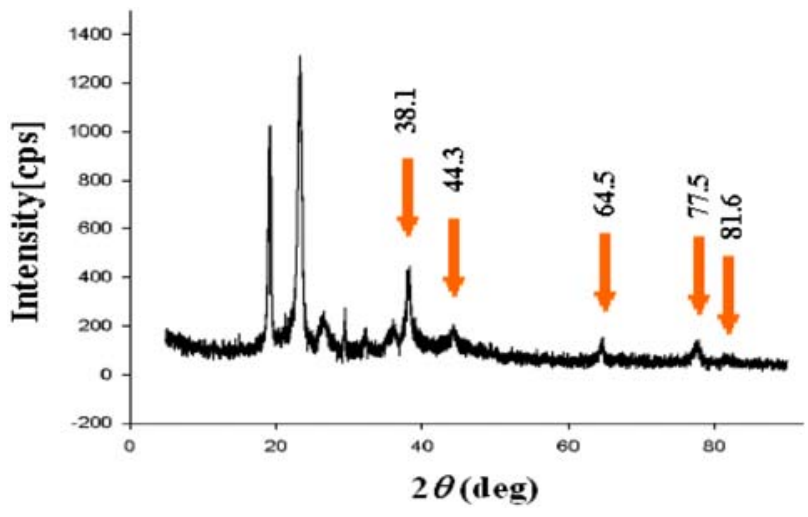

Figure 6. XRD pattern of PEO-sulfadiazine-stabilized silver nanoparticles.

The crystalline structure of nanoclusters can be determined by their X-ray diffraction (XRD) as shown in Figure 6. While the peaks in the range of $20^{\circ} \sim 30^{\circ}$ had to arise from the PEO crystalline structure, ${ }^{27}$ the XRD pattern of the water-dispersible Ag nanoparticles stabilized by PEO-sulfadiazine conjugate shows five specific peaks at $38.1^{\circ}, 44.3^{\circ}$, $64.5^{\circ}, 77.5^{\circ}$, and $81.6^{\circ}$, which correspond to the $\{111\},\{200\}$, $\{220\},\{311\}$, and $\{222\}$ lattice planes of the face-centered cubic (fcc) lattice, respectively. ${ }^{28}$ All nanoclusters obtained from this experiment exhibited the similar lattice images to the above one. Therefore, the water-dispersible silver nanoparticles stabilized by PEO-sulfadiazine seem to be the same single crystallite with the fcc structure as that of the bulk Ag single crystal. ${ }^{28}$

PEO-vancomycin conjugate was successfully synthesized as shown in Scheme I. The vancomycin group at the chainend also contains several functional groups such as hydroxyl, carboxyl, amine, and chloride as shown in Figure 1(b). Considering this situation, nano-sized silver particles are expected to be also stabilized effectively by PEO-vancomycin conjugate. Figure 7 shows SECs of poly(ethylene oxide) and the corre-

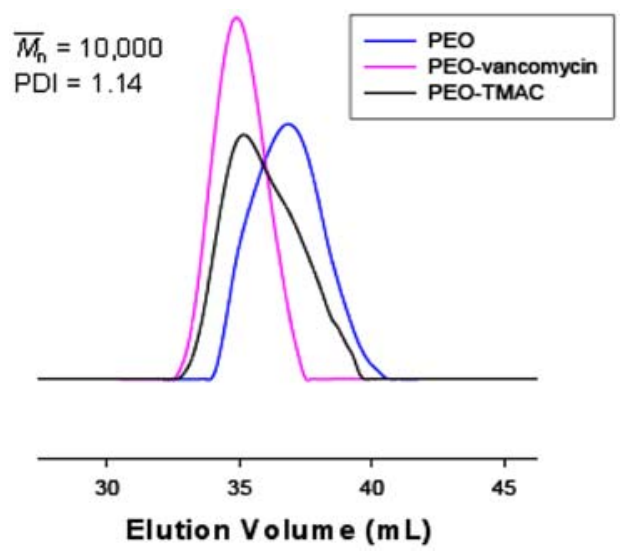

Figure 7. Comparison of size exclusion chromatograms of PEO, $\omega$-anhydride PEO (PEO-TMAC), and PEO-vancomycin conjugate in distilled water as an eluent. 
sponding functionalized PEO. The molecular weight distribution of $\omega$-anhydride-functionalized PEO looks like multimodal arising from incomplete globular coil in distilled water or a side reaction resulting in the generation of coupled product. However, PEO-vancomycin conjugate exhibts monomodal distribution. The observed molecular weight of PEO-vancomycin conjugate was $M_{n, o b s}=10,000 \mathrm{~g} / \mathrm{mol}$ compared with the PEO standard samples. The results for ${ }^{1} \mathrm{H}$ NMR spectroscopic characterization of PEO-vancomycin conjugate inform that the functionalization yield was ca. 60 mol-\% based on comparison of incipient amount of poly(ethylene oxide) used. Practically, the coupled poly(ethylene oxide) itself produced from the reaction of trimellitic anhydride chloride with polymeric alkoxide seemed to be readily removed via purification process of $\mathrm{PEO}$-vancomycin conjugate.

Figure 8 shows the UV/Visible spectra of vancomycin, $\omega$ -

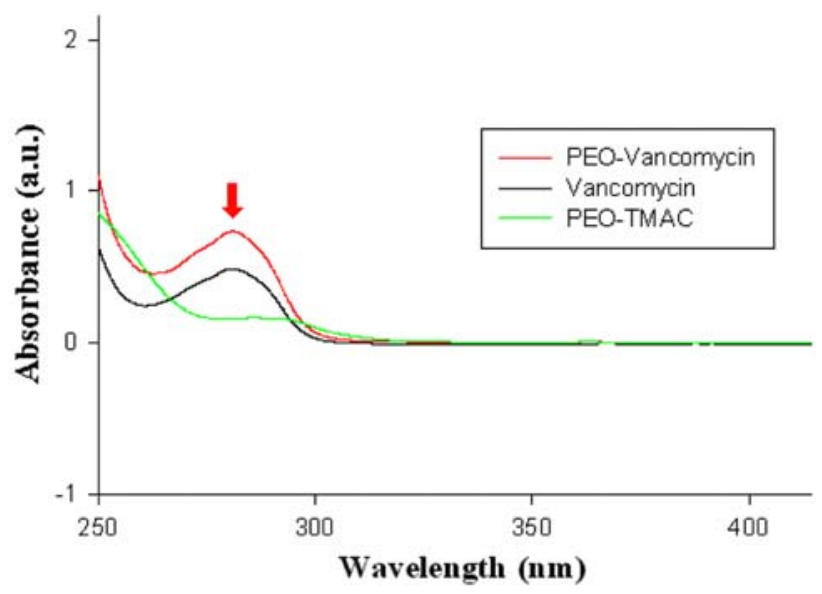

Figure 8. The electronic spectral change of vancomycin itself, $\omega$ anhydride-PEO (PEO-TMAC), and PEO-vancomycin conjugate in distilled water. anhydride PEO (PEO-TMAC) and PEO-vancomycin conjugate in distilled water. While a weak maximum absorption peak of PEO-TMAC appears near $290 \mathrm{~nm}$ corresponding to electronic state on the aromatic ring, the strong absorption peak near $290 \mathrm{~nm}$ of PEO-vancomycin conjugate in distilled water follows that of vancomycin itself in distilled water. This informs that purified PEO-vancomycin conjugate must contain the vancomycin unit at the chain end.

The preparation of nano-sized silver clusters was performed in distilled water by following the analogous procedures to those in the case of preparation of PEO-sulfadiazinestabilized Ag nanoparticles except for the reaction media. Figure 9 represents TEM image and its ED pattern. The particle size distribution is in the range of $5-20 \mathrm{~nm}$. The particles must retain a crystalline structure on the basis of selected area electron diffraction (ED) pattern. The bright spots on the rings of the ED pattern seem to arise from the PEO chains not joining in stabilization of silver particles in the aggregates as shown in the TEM image. Concerning these results, PEO-conjugated pro-drugs carrying functional groups at the chain-end must be effective to stabilize silver nanoparticles.

\section{Conclusions}

We have successfully synthesized $\omega$-functionalized PEOs containing the drug moieties. The reaction of $\omega$-anhydridefunctionalized PEO with sulfonamide or vancomycin led to production of the corresponding PEO-conjugated prodrugs. The functionalization yields were ca. $98 \mathrm{~mol}-\%$ and 60 mol-\% for sulfadiazine and vancomycin, respectively. The unfunctionalized fractions of both of them were readily removed via selective precipitation from solubility difference between two fractions. Using PEO-based con-
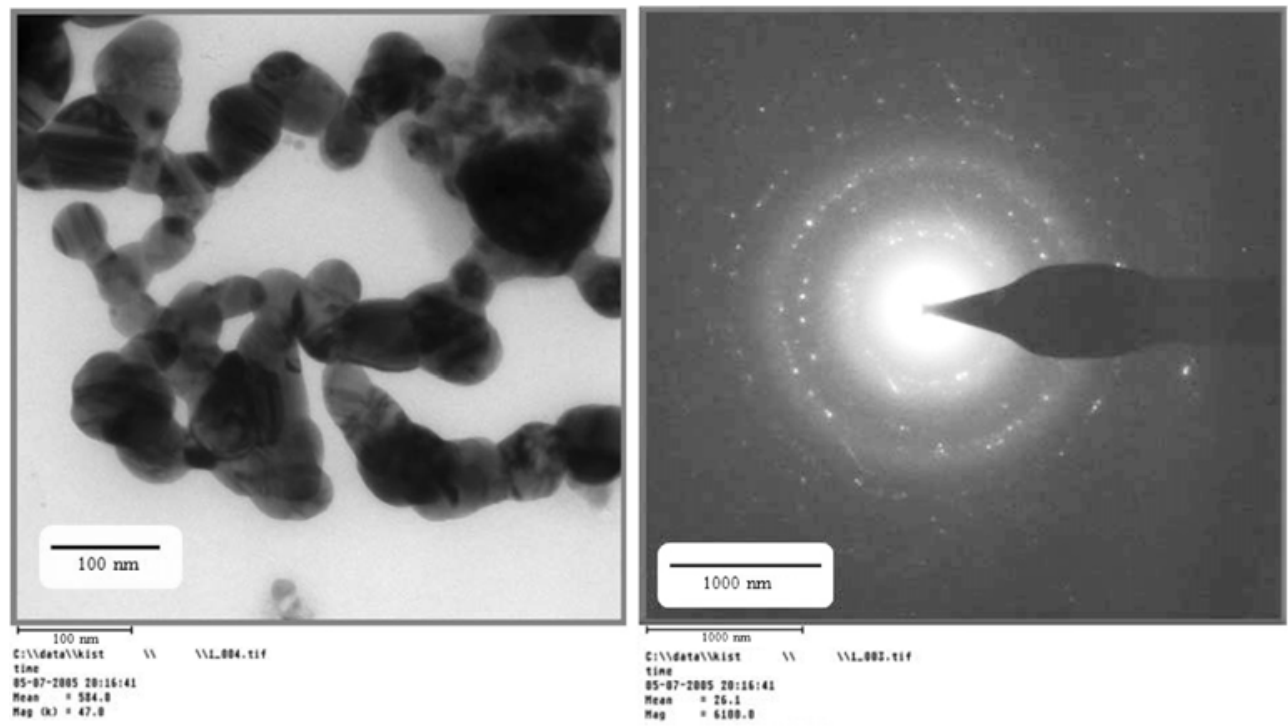

Figure 9. TEM image and the ED pattern of PEO-vancomycin conjugate-stabilized Ag nanoparticles in distilled water. 
jugates, nano-sized silver particles were prepared in water or methanol and the resulting nanoparticles were stable in air or in water over a month. Specifically, PEO-sulfadiazine-stabilized Ag nanoparticles exhibit the fcc crystallite structure like bulk silver. These materials are expected to be used for the biomedical field. Further studies on their applications will be our task.

Acknowledgement. We would like to thank the Kyunghee University Research Program (Grant No. 20070611).

\section{References}

(1) C. B. Murray, S. Sun, H. Doyle, and T. Betley, Mater. Res. Soc. Bull., 26, 985 (2001).

(2) B. Wiley, Y. Sun, J. Chen, H. Cang, Z.-Y. Li, X. Li, and Y. Xia, Mater. Res. Soc. Bull., 30, 356 (2005).

(3) Y. Sun and Y. Xia, Science, 298, 2176 (2002).

(4) J. Wang, G. Liu, and A. Merkovi, J. Am. Chem. Soc., 125, 3214 (2003).

(5) R. Bau, J. Zhang, E. J. Beckman, M. Virji, W. A. Pasculle, and A. Wells, Biomaterials, 27, 4304 (2006).

(6) A. Panacek, L. Kvitek, R. Prucek, M. Kolar, R. Vecerova, N. Pizurova, V. K. Sharma, T. Nevecna, and R. Zboril, J. Phys. Chem. B, 110, 16248 (2006).

(7) R. W.-Y. Sun, R. Chen, N. P.-Y. Chung, C.-M. Ho, C.-L. S. Lin, and C.-M. Che, Chem. Commun., 5059 (2005).

(8) L. Lu, A. Kobayashi, K. Tawa, and Y. Ozaki, Chem. Mater., 18, 4894 (2006).

(9) X. Zou and S. Dong, J. Phys. Chem. B, 110, 21545 (2006).

(10) E. V. Schevchenko, D. V. Talapin, H. Schnablegger, A. Kornowski, O. Festin, P. Svedlindh, M. Haase, and H. Weller, J. Am. Chem. Soc., 125, 9090 (2003).

(11) R. Narayanan and M. A. El-Sayed, J. Am. Chem. Soc., 125, 8340 (2003)

(12) B. J. Wiley, S. H. Im, Z.-Y. Li, J. McLellan, A. Siekkinen, and Y. Xia, J. Phys. Chem. B, 110, 15666 (2006).

(13) B. J. Wiley, Y. Sun, B. Mayers, and Y. Xia, Chem. Eur. J., 11,
454 (2005).

(14) A. Gupta and S. Silver, Nature Biotechnol., 16, 888 (1998).

(15) J. R. Morones, J. L. Elechiguerra, A. Camacho, K. Holt, J. B. Kouri, J. T. Ramirez, and M. J. Yacaman, Nanotechnology, 16, 2346 (2005).

(16) M. Moskovits and J. S. Suh, J. Am. Chem. Soc., 107, 6826 (1985).

(17) R. P. Cheung and J. T. DiPiro, Pharmacotherapy, 6, 153 (1986).

(18) H. Ringsdorf, J. Polym. Sci. Symp., 51, 135 (1975).

(19) C. T. Supuran, A. Casini, and A. Scozzafava, Med. Res. Rev., 23, 535 (2003).

(20) M. Morton and L. J. Fetters, Rubber Chem. Technol., 48, 359 (1975).

(21) J. Kim, S. Choi, K. M. Kim, C. H. Lee, H. S. Park, S. S. Hwang, S. M. Hong, S. Kwak, and H.-O. Yoo, Macromol. Symp., 245/246, 565 (2006).

(22) H. Gilman and F. K. Cartledge, J. Organomet. Chem., 2, 447 (1964).

(23) J. Kim, S. Choi, K. M. Kim, D. H. Go, H. J. Jeon, J. Lee, H. S. Park, C. H. Lee, and H. M. Park, Macromol. Res., 15, 31 (2007).

(24) J. M. Harris and R. B. Chess, Nature Rev. Drug Dis., 2, 214 (2003).

(25) B. Wiley, Y. Sun, B. Mayers, and Y. Xia, Chem. Eur. J., 11, 454 (2005).

(26) D. E. Sands, Introduction to Crystallography, Dover, New York, 1993, p 51.

(27) M. S. Lisowski, Q. Liu, J. Cho, J. Runt, F. Yeh, and B. S. Hsiao, Macromolecules, 33, 4842 (2000).

(28) (a) S. Panigrahi, S. Praharaj, S. Basu, S. K. Ghosh, S. Jana, S. Pande, T. Vo-Dinh, H. Jiang, and T. Pal, J. Phys. Chem. B, 110, 13436 (2006). (b) S. He, J. Yao, S. Xie, H. Gao, and S. Pang, J. Phys. D: Appl. Phys., 34, 3425 (2001). (c) Y. Gao, P. Jiang, D. F. Liu, H. J. Yuan, X. Q. Yan, Z. P. Zhou, J. X. Wang, L. Song, L. F. Liu, W. Y. Zhou, G. Wang, C. Y. Wang, S. S. Xie, J. M. Zhang, and D. Y. Shen, J. Phys. Chem. B, 108, 12877 (2004). (d) H. Xia, Y. Zhang, S. Sun, and Y. Fang, Colloid Polym. Sci., 285, 1655 (2007). 